\title{
THE NEW FACILITATORS' STRATEGIES IN MANAGING ONLINE DISCUSSION OF THE SECOND IMOOC
}

\author{
Hidayah Nor \\ UIN Antasari Banjarmasin \\ Hidayahnor616@gmail.com
}

\begin{abstract}
The purpose of this research was to describe qualitatively the second MOOC new facilitators' strategies in managing online discussion. There were eight new facilitators who came from different regions in Indonesia such as Rembang, Salatiga, Surabaya, Solo, Semarang, Malang, and Banjarmasin. The data were collected through a Questionnaire. The results of this research shown that there are various strategies that have been applied by the new facilitators including design questions that particularly get on-topic discussion carefully, help online learners in providing a guideline for the preparation on-topic responses, present rules for those who choose off-topic comments explicitly, state the expectation for online discussions participants to stay on a topic, set alternative locations for off-topic discussions, screen all postings and put offtopic posts to alternative locations with an explanation to participants, incorporate a reminder that responses stay on a topic with all posted questions, reword the original question when responses are going in the wrong direction, provide discussion summary regularly, give warning privately and corrective suggestions to learners who submit off-topic comments, give a reward for those who keep on a topic, and offer a grade for those who keep on a topic. This is really helped the second Indonesian MOOC participants to make the discussions contains more cognitive presences and they can accomplish the course and gain a new knowledge from this online course.
\end{abstract}

Keywords: IMOOC; facilitators' strategies; Indonesian Massive Open Online Course; online discussion

\section{BACKGROUND}

The definition of MOOCs is actually the integration and connectivity of social networking, facilitation of recognized experts in a field of study, and a collection of accessible online resources. MOOCs need to be inherently scalable and may share conventions of common course, such as agreed timeline and weekly topics but typically free, no prerequisites other than internet access and participants' interest to the course, no expectations for participation, and no formal accreditation. Some prominent MOOCs, such as various classes from Stanford University, edX, Coursera and Udacity, have attracted tens of thousands of participants. Even though the convention rates may be very low, but huge popularity in starting students' shows the successful of MOOCs. 
Indonesian Massive Open Online Course (IMOOC) focused on Technology for Autonomous Learning was designed by Regional English Language Office (RELO) and The U.S. Embassy in Jakarta worked with fifteen Indonesian university professors from around Indonesia to develop this course, the first Indonesian-developed IMOOC created solely for Indonesian participants. The developers were guided during the development by two English Language specialists, Santi Budi Lestari of University of Indonesia and Debra Lee of Vanderbilt University in Nashville, Tennessee.

During the creation process, the Indonesian developers learned how to use the free version of the Canvas E-Learning platform, created suitable materials for autonomous learning, and worked together as in teams to ensure that participants of the program receive the best instruction possible. RELO's office considers them the Rock stars of online course development in Indonesia.

There are five modules to aid in the understanding of autonomous learning and provide with the skills to support you in creating your own autonomous classroom. Each module ran for two weeks with activities and discussions to support your learning.

1. Module 1 : Understanding Autonomous Learning

2. Module 2 : Digital Literacy

3. Module 3 : Mobile Devices for Autonomous Teaching and Learning

4. Module 4 : Promoting Autonomous Learning Using Videos

5. Module 5 : Autonomy through Video Creation

At the end each module, the participants have a project to do in which they made use of the skills they have gained. The products of these projects kept in the E-portfolio that they have to create. In other words, E-portfolio consisted of a collection of their work throughout the course.

The discussions session is very important to evaluate the participants' understanding about the materials provided in the modules and they have to answer the questions based on their own experience in teaching and learning process and also based on the theories.

\section{The Role of the Instructors in Online Learning}

There are many roles of the instructor in online learning which can be seen as a facilitator, a mentor, or a coach. Their essential role is to overcome incoherence, provide feedback and scaffold student learning. Positive correlation was found between teacher immediacy behaviours and student learning based on the research of Sanders \& Wiseman, (1990). Furthermore, Rovai (2001) also reminded instructors to provide students a reasonable amount of time and opportunity to respond the questions. Immediacy behaviors of the instructor and student expectations may influence student learning and metacognitive processes so that they should structure a feedback mechanism that will encourage student inquiry, collaboration and metacognitive feedback and self-assessment strategies.

The facilitators can give the motivation to the participants of online course by engaging them in productive discussions and describe the expectation of the online course briefly in form of discussion rubric and this has already happened in Indonesian MOOC 2018. In addition, discussion forums for socio-emotional that have the goal of nurturing a strong sense of community within the course and group discussion forums for content-and task-oriented on authentic topics are also needed to promote. One of the important factors in discussions to be effectively, instructors should generate a social presence in the virtual classroom and avoid becoming the center of all discussions by emphasizing participants' 
interactions, as stated by Garrison, D. R., Anderson, T., and Archer, W. (2001) in their research of critical thinking, cognitive presence, and computer conferencing in distance education for attending the issues of social equity arising from use of different communication patterns by culturally diverse students.

\section{The Way to Manage Online Discussions}

There are three important points to be considered in managing online discussion. First, at the beginning: Set the tone and style of the discussion postings of the students whether in the formal or informal ways. Describe and give examples of thoughtful and courteous posts and also acceptable language and behavior and to require all participants to identify by name. Second, throughout the discussion: allowing participants to talk in order to encourage interaction and discourage directing posts to the instructor. Ask probing questions in prompt discussion by asking for clarification or evidence and give them a supportive response. The last for the end of the discussion: Ensure closure through synthesis and summary and assign this task and other moderating roles to individual students.

\section{Facilitating Online Discussions}

There are five considerations and strategies in facilitating online discussion that have been discussed by some experts in order to make the online learning discussion successful.

The first is to develop and maintain a social presence in discussion forums. Researchers such as Garrison, et al (2001), Morgan \& Tam (1999) stated that social presence can help reduce or eliminate negative outcomes of the participants and also researches evidence support the effectiveness of specific and timely feedback for enhancing task performance (Bangert, 2004). Additionally, social presence among members of a learning community increases discourse, facilitates the critical thinking, strengthens sense of community, promotes learner satisfaction, facilitates collaborative learning, and contributes directly to the success of the learning experience (Garrison \& Anderson, 2003; Gunawardena \& Zittle, 1997).

The second is to emphasize student-to-student interactions in online course to encourage construction of knowledge through interactions among students as they reflect on the issues prior to the instructor making a teaching point. Each student helps others learn and as well as getting help from other students so that all members of the learning community are actively involved in the teaching-learning process.

The third is to attend to issues of social equity based on different cultural communication patterns. There are verbal and nonverbal components in communication. The greater the cultural differences between online communicators, the greater the potential for miscommunication

The fourth is concerning the issues of social equity based on different gender-based communication patterns and facilitators of online discussion need to be attentive to communication patterns by some students that may silence other students.

The instructors must pay particular attention to unequal participation of students in group work and employ strategies to address status problems based on Theory of Complex Instruction as proposed by Cohen (1997) which is a classroom management system where instructors delegate authority to students, through norms and roles, to generate student interactions. Cohen (1994) recommends that the instructor makes the case to students that everyone in a group needs each other for successful completion of the work and no one has all the abilities necessary for the assignment, but each student possesses some. 


\section{METHOD}

This research is a descriptive qualitative research which tries to explore the new facilitators' strategies in managing online discussion of Indonesian MOOC 2018

The subject of this research is eight new facilitators of IMOOC 2018 around Indonesia which was located in Salatiga, Banjarmasin, Surabaya, Rembang, Solo, Semarang, and Malang.

In conducting this research, the instrument to be used is the questionnaire in the form of Google form that has to be filled by the respondents and also free interview through online communication with the new facilitators. This is the link for Google form: http://bit.ly/Survey_on_managing_online_discussion.

All the collected and processed data are analyzed descriptively and qualitatively. Data analysis in a process by which data simplified into a form can be interpreted and read easily by describing the result of the questionnaire one by one detail.

\section{FINDING AND DISCUSSION}

This part deals with the result of the research based on some facts found in the data. It covers the new facilitators' strategies in managing online discussion of IMOOC 2018.

These are the results of questionnaire to the IMOOC 2018 new facilitators:
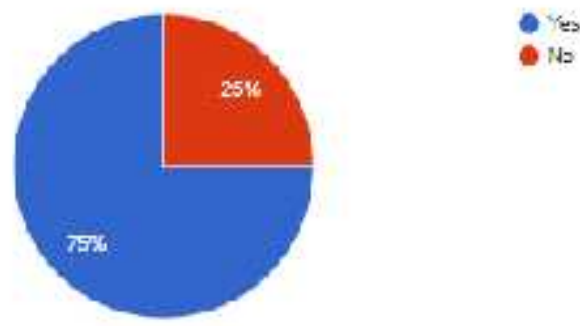

Figure 1. Designing questions that specifically elicit on-topic discussion

Based on the result of the first question related to design the questions on the discussion based on the topic given, $75 \%$ (6 out of 8 ) stated yes and $25 \%$ (2 out of 8 ) stated no. It means that most of the facilitators have already made the questions carefully related on the discussion topic of Indonesian MOOC.
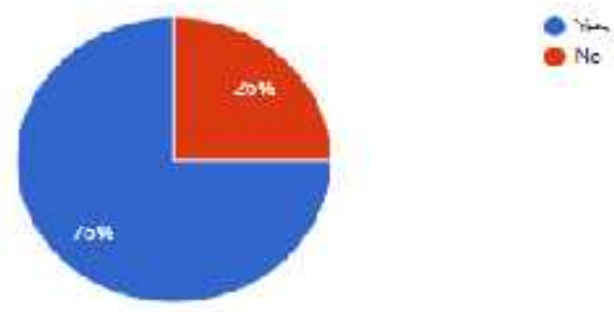

Figure 2. Guidelines to help online learners prepare on-topic responses 
It can be seen from the figure above the responses of the facilitators consist of $75 \%$ stated yes and $25 \%$ stated no. it means that they really helped the participants to participate well in the discussion by providing guidelines to make the discussion stayed on track.

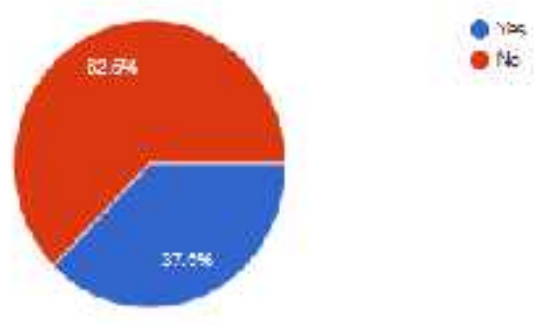

Figure 3. Rules of conduct that eliminate off-topic comments

The third question focused on presenting rules to reduce the comments which do not relate to the topic given and $65 \%$ of facilitators agreed that they have already presented the rules for the participants while $37.5 \%$ stated no.

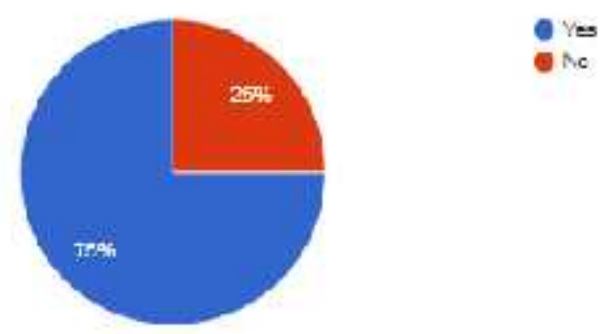

Figure 4. Expectation that online discussions stay on topic

The online discussions should stay on topic and the facilitators should state their expectation toward the discussion. Based on the result of the questionnaire, it can be stated that $75 \%$ of them stated yes and considered that it is important for the participants to know the expectation however $25 \%$ of them stated no and they did not expect anything from their participants.

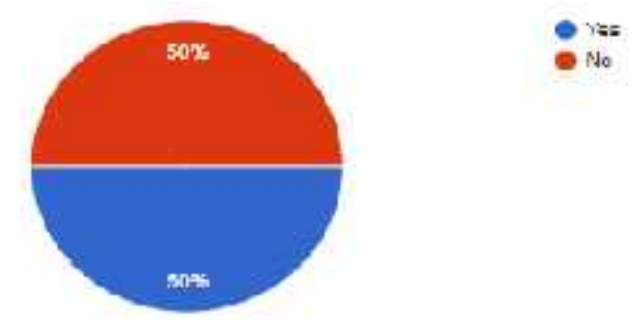

Figure 5. Alternative locations for off-topic discussions

Surprisingly for the next question related to providing alternative locations for the topics that do not connect to online course matters, $50 \%$ of facilitators stated yes and they provide it by using social media such as Whatsapp application and made Whatsapp group 
for participants to facilitate the location for confirmation and avoid misunderstanding about the topics. On the other hand, $50 \%$ of facilitators did not provide alternative locations for off topic discussions and just focused on using canvas as the learning management system for the online course.

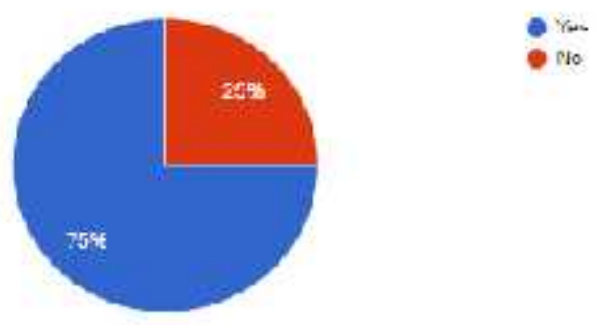

Figure 6. Alternative locations with an explanation to the submitter

For the next questions about anticipating off topic posts that have been made by the participants, the facilitators who have already made the alternative locations for those posts screened all postings to the submitter so that they can know that their answers towards the discussions still off topics and they have to revised it. The percentage for facilitators who screened is $75 \%$ while the other $25 \%$ stated no.

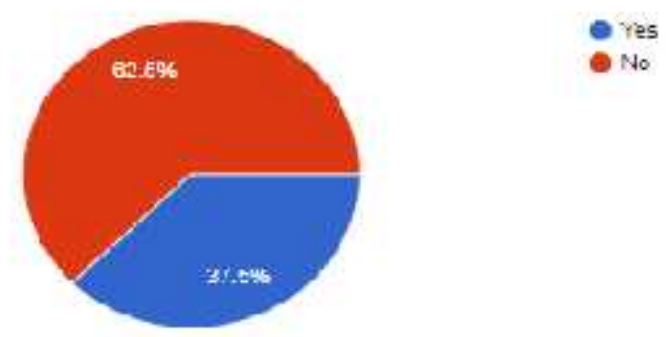

Figure 7. A reminder that responses stay on topic with all posted questions

In online course system, actually reminder is very important for the participants because they have various topics for the course and sometimes they forget about the topics discussed, because of that matter facilitators can include a reminder for responding the participants' answers to stay on topic discussions. Based on the chart just $37.5 \%$ of facilitators stated yes and $62.5 \%$ stated no and considered that it does not matter for them to do not remind the participants about responding related to the topics.
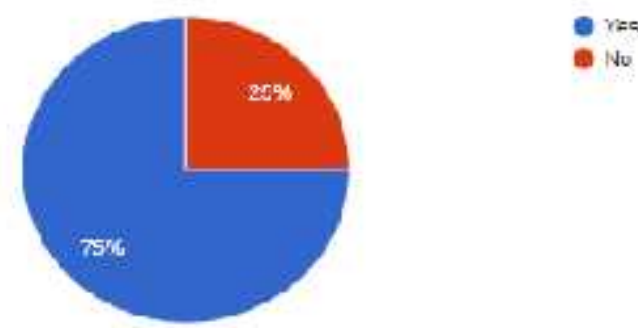

Figure 8. Reword the original question

In responding the questions of online course, participants sometimes can go in the wrong direction and they answers do not have the relation with the topics. For this case, the 
facilitators can remake the sentences of original questions for the participants' understanding and in fact $75 \%$ of facilitators have already done that and $25 \%$ of facilitators stated no.

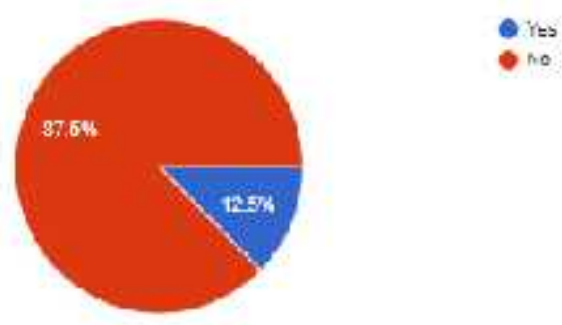

Figure 9. Discussion summary on a regular basis

Actually for providing discussion summary is not part of facilitators' tasks and it does not require in this online course, however when the researcher asked them about this question, $12.5 \%$ of them stated yes and $87.5 \%$ of them stated no and they thought that it is not really important because the participants can make the summary by themselves if they want.

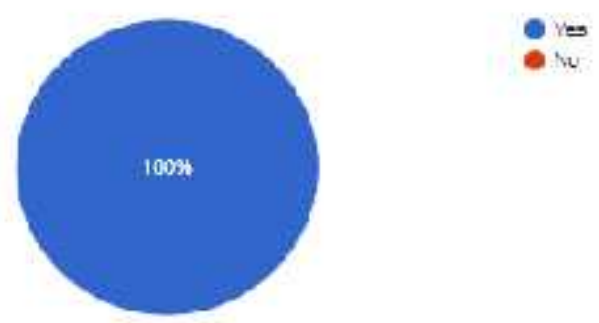

Figure 10. Corrective suggestions to learners who submit off-topic comments

All the facilitators (100\%) agreed that corrective suggestions is very important for the participants when they made off topic comments for the discussions so that they can revise their comments related to the topics and other participants do not get the wrong direction in the discussion.

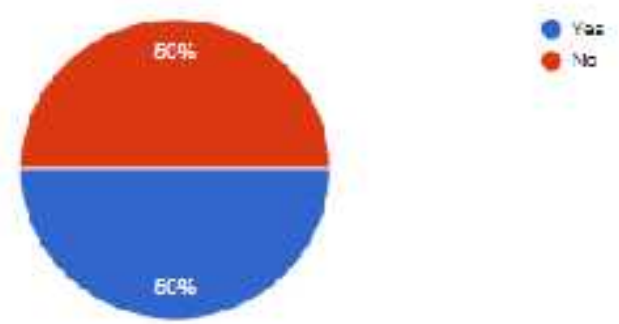

Figure 11. Reward for keeping on topic

Regarding the rewards for those who keeping on topic for the discussion, $50 \%$ of facilitators stated that they provided a reward for the participants and 50\% of them stated no. however, rewards actually just an option to appreciate participants' effort in the discussion. 


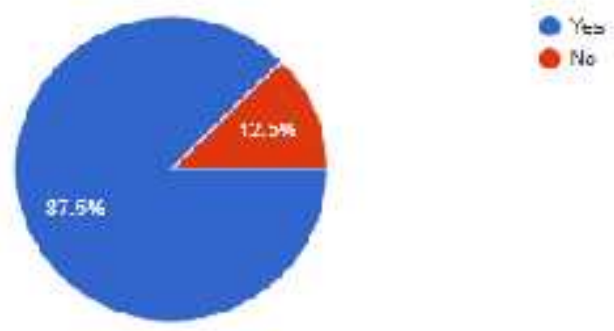

Figure 12. Grade for keeping on topic

In the second Indonesian MOOC 2018, grade is very important for the participants to make them passed the course by achieving the minimal grade of the course which $70 \%$ of all their assignments. Thus, $87.5 \%$ of facilitators provided an additional grade for participants who keep on topic discussion but $12.5 \%$ did not think that it is important and just keep going with common grade.

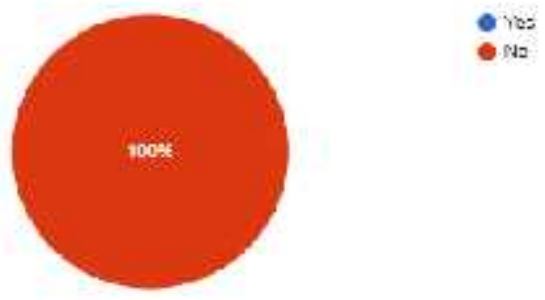

Figure 13. Expel offenders from the discussion after several of off-topic submissions

The last question related to the offenders or the participants who have submitted several off topic submissions for the discussion, all the facilitators (100\%) stated that they did not quit them automatically from the discussions and still give them chance to be better for the next discussions and give their responses appropriate with the discussion topics.

The following is the additional information about other strategies that have applied by the new facilitators which obtained from free interview.

1. Giving responses in the forms of compliments, triggering questions, confirmations, and additional information to most participants' answers in the discussions 2. Updating the number of discussions almost daily in the form of page screenshot sharing in our WA group 3. Reminding the deadline of discussions in our WA group (MH, Salatiga).

2. Feedbacks were given in the comment box. If a participant submitted an off-topic comment, for me, it would be better to give the suggestion in a private chat, instead of correcting them in the Canvas discussion forum (Y, Banjarmasin)

3. Regarding participants whose discussion entries made little reference to the previously introduced material or any other external resources, I privately reminded them of requirement and used a peer's model answer as an example. This mild form of reprimand was all done personally through the Canvas Scoring feature (Speed Grader). In the social media group (Whatsapp), I acknowledged participants who have successfully fulfilled all the discussion requirements (by mentioning their names) to show the quality of work expected in this course (PP, Surabaya) 
4. Before publishing each module, I told the participants about the material that they had to learn and the task that they had to do. Therefore, they could firstly browsed the information related to the material from the internet. Then, we discussed about itu through WA group (ALH, Rembang)

5. Since my participants were adult learners, both off and on topics were given appreciation to motivate their willingness to join discussion forum. However, the off topics will be given leading question to guide my participants on the right track after the appreciation expression (NRT, Surabaya)

6. I reminded participants in informal ways in a group chat and invite others to share what they think of a certain question or post another question to invite more discussion in canvas posts (SAA, Solo)

7. Keep maintaining our good relationship with the participants in many ways. Use social media or instant messenger to do so (DG, Malang)

There are some theories and previous studies related to the findings of the research to make the results of this study stronger and supported by the theories. The first is from Fox $\&$ Patterson (2012) who have MOOC on their introductory programming. They are allowing and requiring the participants to be more active in their online learning demanding them to go deeper and adding incentives for participant retention by treating the course as a formal entrance exam to their degree in Computer Science and Information Technology field.

Another research finding of Vonderwell (2003) implied that online learning facilitators need to carefully utilize the web technologies for collaboration and interaction because it will influence students' reflection and building of shared experiences. This study enhances or supports collaborative, reflective, and meaningful learning and the students had varying experiences and perspectives within their learning. It is also will help learners to improve motivation and help facilitate interpersonal/social interaction in online classroom.

On the other hand, Beaudin (1999) suggested that online discussion can be done by carefully designing good questions, providing guidelines, rewording the question when discussions go off topic, and by providing discussion summaries. In addition, the technique of designing good questions is a key to good teaching and learning. Taba described as cited in Beaudin (1999) questioning as the single most influential teaching act since the ability of questions influence the learning process.

\section{CONCLUSION}

This research focused on describing the new facilitators' strategies in managing online discussion of Indonesian MOOC 2018 through the online questionnaire and free interview. The findings showed that there were some strategies that have been applied by the new facilitators around Indonesia including design questions based on the topic of discussion, help participants by providing a guideline for on-topic responses, give rules and warnings for off-topic comments, tell the expectation for online discussions participants to stay on a topic, give alternative locations for off-topic discussions, screen all postings and put off-topic posts to alternative locations, remind the participants to give responses stay on a topic, reword the original question when responses are going in the wrong direction, write discussion summary, give warning privately and corrective suggestions to learners who submit off-topic comments, give a reward and a grade for those who keep on a topic. For future researchers can be more focused on the wider population of facilitators of other online courses in Indonesia and all over the worlds. 


\section{REFERENCES}

Anderson, T., Liam, R., Garrison, D. R., \& Archer, W. (2001). Assessing teaching presence in a computer conferencing context.

Beaudin, B. P. (1999). Keeping online asynchronous discussions on topic. Journal of Asynchronous Learning Networks, 3(2), 41-53.

Cohen, S. G., \& Bailey, D. E. (1997). What makes teams work: Group effectiveness research from the shop floor to the executive suite. Journal of management, 23(3), 239-290.

Cohen, J. L., \& Arato, A. (1994). Civil society and political theory. MIT press.

Davis, B.G (2009). Tools for teaching. San Francisco, CA: Jossey-Bass.

DeNoyelles, A., Zydney, J.M., \& Chen, B. (2014). Strategies for creating a community of inquiry through online asynchronous discussions. MERLOT Journal of Online Learning and Teaching, 10(1), 153-165.

Dignath, C. (2016). What determines whether teachers enhance self-regulated learning? Predicting teachers' reported promotion of self-regulated learning by teacher beliefs, knowledge, and self-efficacy. Frontline Learning Research, 4(5), 83-105.

Ellis, R. A., Goodyear, P., Prosser, M., \& O'Hara, A. (2006). How and what university students learn through online and face to face discussion: Conceptions, intentions and approaches. Journal of Computer Assisted Learning, 22(4), 244-256.

Fox \& Patterson. 2012. Crossing the software education chasm. Commn. ACM, 55(5):44-49

Garrison D.R. \& Cleveland-Innes, M. (2005). Facilitating cognitive presence in online learning: Interaction is not enough. American Journal of Distance Education, 19(3), 133-148.

Garrison, D. R., Anderson, T., \& Archer, W. (2001). Critical thinking and computer conferencing: A model and tool to assess cognitive presence.

Garrison, D. R., Anderson, T., \& Archer, W. (2001). Critical thinking, cognitive presence, and computer conferencing in distance education. American Journal of distance education, 15(1), 7-23.

Garrison, D. R., Anderson, T., \& Archer, W. (2003). A theory of critical inquiry in online distance education. Handbook of distance education, 1, 113-127.

Gunawardena, C. N., \& Zittle, F. J. (1997). Social presence as a predictor of satisfaction within a computer mediated conferencing environment. American journal of distance education, 11(3), 8-26.

Hall, B.M. (2015, April). You're asking the wrong question. Faculty Focus. Questions for a Socratic Dialogue (PDF). Virginia Tech College of Engineering, Department of Computer Science.

John, D. (2018). Learning LSRW Skills through Active Student-Involvement: Screening An Edited Film. Teaching English with Technology, 18(2), 115-128.

Morgan, C. K., \& Tam, M. (1999). Unravelling the complexities of distance education student attrition. Distance education, 20(1), 96-108.

Rourke, L., Anderson, T., Garrison, D. R., \& Archer, W. (2001). Methodological issues in the content analysis of computer conference transcripts. International journal of artificial intelligence in education (IJAIED), 12, 8-22.

Rovai, A. (2007). Facilitating online discussions effectively. The Internet and Higher Education, 10, 77-78. 
Sanders, J. A., \& Wiseman, R. L. (1990). The effects of verbal and nonverbal teacher immediacy on perceived cognitive, affective, and behavioral learning in the multicultural classroom. Communication Education, 39(4), 341-353.

Vihavainen, A., Luukkainen, M., \& Kurhila, J. (2012, October). Multi-faceted support for MOOC in programming. In Proceedings of the 13th annual conference on Information technology education (pp. 171-176). ACM.

Vonderwell, S. (2003). An examination of asynchronous communication experiences and perspectives of students in an online course: A case study. The Internet and higher education, 6(1), 77-90.

Vonderwell, S., Liang, X., \& Alderman, K. (2007). Asynchronous discussions and assessment in online learning. Journal of Research on Technology in Education, 39(3), 309-328.

Zhou, H. 2015. A systematic review of empirical studies on participants' interactions in internet-mediated discussion boards as a course component in formal high education settings. Online Learning Journal, 19(3). 